\title{
Unmanned aerial systems for precision forest inventory purposes: A review and case study
}

\author{
by Tristan R.H. Goodbody ${ }^{1, *}$, Nicholas C. Coops ${ }^{1}$, Peter L. Marshall1 ${ }^{1}$, Piotr Tompalski ${ }^{1}$, Patrick Crawford ${ }^{2}$
}

\begin{abstract}
Unmanned Aerial Systems (UAS) are capable of improving the efficiency of acquisition and providing fine spatial scale data for sustainable resource management. In this paper we begin by describing differences between UAS airframes, their successes and limitations, and list contemporary research applications. UAS compatible sensor technologies are discussed, including passive and active sensors. Finally, we detail a case study where UAS updated an Enhanced Forest Inventory (EFI) for a study area in interior British Columbia. Airborne Laser Scanning (ALS) from 2013 and Digital Aerial Photogrammetric (DAP) point clouds acquired using a UAS from 2015 were used to estimate individual tree height and volume increments. A total of 246 trees were detected using Canopy Height Models (CHMs) with $70 \%$ of these trees being matched in the ALS and DAP data sets. Mean tree growth between 2013 and 2015 from the CHM and 95 ${ }^{\text {th }}$ percentile of height (P95) was estimated at $0.68 \pm 0.05$ and $0.50 \mathrm{~m} \pm 0.05 \mathrm{~m}$, respectively. Similarly, mean gross tree volume increments $\left(\mathrm{m}^{3}\right)$ were computed as $0.05 \mathrm{~m}^{3} \pm 0.005 \mathrm{~m}^{3}$ and $0.03 \mathrm{~m}^{3} \pm 0.005 \mathrm{~m}^{3}$ for the CHM and P95, respectively. The results indicate that information from UAS-DAP point clouds can generate spatially and temporally accurate inventories and have potential to inform a number of sustainable forest management activities.
\end{abstract}

\section{RÉSUMÉ}

Les systèmes aériens sans pilote ou drones (Unmanned Aerial Systems -UAS) peuvent rendre plus efficace l'acquisition des données et en raffiner l'échelle spatiale pour l’aménagement forestier durable. Dans cet article, nous allons d'abord distinguer les différentes plateformes UAS aéroportées, voir leurs capacités et leurs limitations et répertorier les applications dans le domaine de la recherche contemporaine. Il sera ensuite question des technologies de capture, incluant les capteurs passifs et les capteurs actifs. Nous décrirons ensuite une étude de cas impliquant des drones pour mettre à jour un inventaire forestier amélioré (Enhanced Forest Inventory - EFI) sur un territoire détude de lintérieur de la Colombie-Britannique. Elle consistait à utiliser des nuages de points obtenus d'une part par lidar aéroporté (ALS) en 2013 et par photogrammétrie aérienne numérique (DAP) à l'aide d'un drone en 2015 pour estimer l'accroissement en hauteur et en volume sur des arbres choisis. On a ainsi pu détecter 246 arbres à laide de modèles numériques de la hauteur du couvert (CHMs) dont $70 \%$ se retrouvaient à la fois dans les données d'ALS et de DAP. La croissance en hauteur moyenne entre 2013 et 2015 d'après le $\mathrm{CHM}$ et le $95^{\mathrm{e}}$ percentile (P95) se chiffraient respectivement à $0,68 \pm 0,05$ et $0,50 \mathrm{~m} \pm 0,05 \mathrm{~m}$. De même on a calculé des accroissements bruts en volume par arbre de $0,05 \mathrm{~m}^{3} \pm 0,005 \mathrm{~m}^{3}$ et $0,03 \mathrm{~m}^{3} \pm 0,005 \mathrm{~m}^{3}$ respectivement avec le CHM et le $\mathrm{P} 95$. Les résultats obtenus laissent voir que les nuages de points obtenus par photogrammétrie aéroportée sur drone (UAS-DAP) peuvent donner des inventaires précis à la foi dans l'espace et dans le temps et constitueraient une source d'information valable pour certaines activités d’aménagement forestier durable.

\section{Introduction}

The forests of Canada cover over $30 \%$ of the nation's land base (Lindquist et al. 2012). In the interest of sustainably maximizing the utility of this resource, a contemporary, dynamic, and consistent description of its state and extent must exist (Wulder et al. 2008). As well as information on the current state of Canada's forests, there is a need for historical information on the state of, and change to, the forested land base to support future policy development and to act informatively on new and emerging issues such as climate change impacts, emerging biotic and abiotic disturbance factors, and adaptive measures to mitigate forest damage (Tomppo et al. 2010).
In order for the Canadian forest industry to remain successful in a global context, forest inventories should be temporally accurate and undertaken at as fine a spatial scale as possible (Hilker et al. 2008). Having easily updatable inventories allow businesses to make informed management decisions on the timing, location, and scale of forest operations. With this in mind, there is a pressing need to have highly dynamic inventory systems that provide forest managers with spatially and temporally accurate feature data at an appropriate cost.

Local forest inventories conducted through intensive ground-based sampling (cruises) have traditionally been used

\footnotetext{
${ }^{1}$ Faculty of Forestry, University of British Columbia, Vancouver, BC, V6T 1Z4, Canada. Corresponding author's email: *goodbody.t@alumni.ubc.ca

${ }^{2}$ Spire Aerobotics Inc., Vancouver, BC, V5Y 1N2, Canada.
} 
for strategic planning to provide managers with fine-scale understanding of timber composition in support of tactical decisions. Technological changes are now making it feasible for regional forest inventories to be used to support tactical decisions involving the timing and location of harvest operations, reducing the need for ground-based sampling. An unpredictable economic climate, increased pressure for environmental stewardship, and evolving policy implications are driving the need for managers to have access to updatable and dynamic forest inventories that optimize the efficiency and sustainability of operational planning (Bechtold and Patterson 2005).

Enhanced Forest Inventories (EFIs) are aimed at improving confidence for forest management decisions and maximizing the return on investment at each step of the commodity supply chain (White et al. 2013b). EFIs, in this context, involve combining traditional inventory data with cuttingedge Airborne Laser Scanning (ALS) technology. The increasingly high spatial and temporal accuracy of EFI products, and three-dimensional (3D) representation of the operating area from tree top through to ground level, provides managers with informative, accurate, and highly customizable representations of operating areas (Bechtold and Patterson 2005).

ALS systems, which have traditionally been attached to manned aircraft, are comprised of a Global Navigation Satellite System (GNSS), an Inertial Measuring Unit (IMU), and a laser sensor (Wehr and Lohr 1999). The GNSS provides accurate geo-spatial tracking of the sensor, while the IMU records physical movements to make pitch, roll, and yaw corrections. A single pulse from an ALS system can be reflected from a number of different objects, resulting in several recorded points, often referred to as first, intermediate, and last echoes. This combination of points, commonly referred to as a point cloud, forms a highly accurate 3D representation of objects on the ground, including the forest canopy, and provides information on individual tree heights, structural complexity, and terrain elevation (Wulder et al. 2008).

The advancement of ALS systems has shown promising results in combination with high resolution satellite imagery with regards to creating accurate datasets for stand level inventory, cover, and structure information (Hilker et al. 2008). Morphological data such as height and crown diameter that were impossible to extract from traditional inventories, unless explicitly measured, are now feasible at the individual tree level (Silva et al. 2014). These metrics provide managers with information that can guide planning and operational decisions without intensive time and costly labour commitments.

Apart from providing information related to above ground vegetation structure, ALS data also provide terrain information in the form of a Digital Elevation Model (DEM). These DEMs are invaluable as they offer detailed sub-metre accuracy information that can improve the effectiveness of operational planning, including designing optimal road and skid trail systems, locating and delineating stream networks, and guiding due diligence programs related to archaeological overview assessments (Wulder et al. 2008).

Once the initial costs associated with implementing an EFI have been resolved, it must be adaptable to reflect forest change. Applying appropriate methods that best facilitate updating EFIs is an ongoing challenge. Acquiring conventional ALS data for small areas is economically inefficient, limiting the practicality of its use for updating operational scale inventory data (Wulder et al. 2008). Two key technologies that are being examined to overcome this issue are Digital Aerial Photogrammetry (DAP) point clouds, to act as supplementary information for updating EFI databases post-harvest or post-disturbance, and Unmanned Aerial Systems (UAS, a.k.a. drones) instead of conventional manned aircraft.

At its most basic level, application of photogrammetry in inventories involves identifying a common location, such as a tree or road intersection, in two or more overlapping images (McGlone et al. 2004). Typically an aircraft with a mounted camera would follow a flight path to ensure total coverage of a given forest area while acquiring images with sufficient overlap (Tao et al. 2011). Upon completion, adjacent aerial images are overlaid and analyzed stereoscopically to outline timber resources and terrain characteristics in $3 \mathrm{D}$. DAP utilises this concept; however, instead of a photo interpreter identifying common objects manually, conjugate pixels are located in overlapping images with digital photogrammetric software. When conjugate pixel pairs are located, a line or ray is superimposed from the vantage point of the camera to their location for each image. The intersection of all rays for one pixel determines its 3D position. This is done for each pixel in all overlapping aerial images using a photo-interpretive algorithm such as Semi-Global Matching (SGM; Hirschmüller 2005). Once complete, each pixel is plotted in $3 \mathrm{D}$ space in the form of a point cloud. These point clouds share multiple similarities to those produced using ALS; however, pixels are used instead of directed light energy (White et al. 2015). Like ALS, DAP point clouds also have the capability to generate DEMs; however, due to the fact that the technology is based on images, the mapping accuracy declines under canopy (Holopainen et al. 2015). Consequently, it is recommended that ALS-derived DEMs be used in forested areas if ALS data are available. Due to the high cost of conventional aerial imagery from airplanes or helicopters, UAS are increasingly being used in the acquisition of high spatial resolution imagery (Pajares 2015). Low long-term capital costs, ease of use, and fast data acquisition are major drivers for their adoption (Tao et al. 2011). UAS have been proven to provide valuable data for surveillance, mapping, and 3D modelling applications (Nex and Remondino 2013).

In this study we provide a demonstration of the use of UAS to acquire imagery and produce DAP point clouds to update forest attributes previously inventoried using ALS. We first discuss platform types and sensor configurations currently available to UAS, and describe the most common sensors and underlying technological approaches being used. We then provide a review of relevant research on current approaches to using UAS for forest management applications. We conclude by highlighting the results of a case study conducted in the interior of British Columbia, which demonstrates the successes and challenges associated with using UAS-DAP point clouds to update estimates of individual tree height metrics and volumes. 


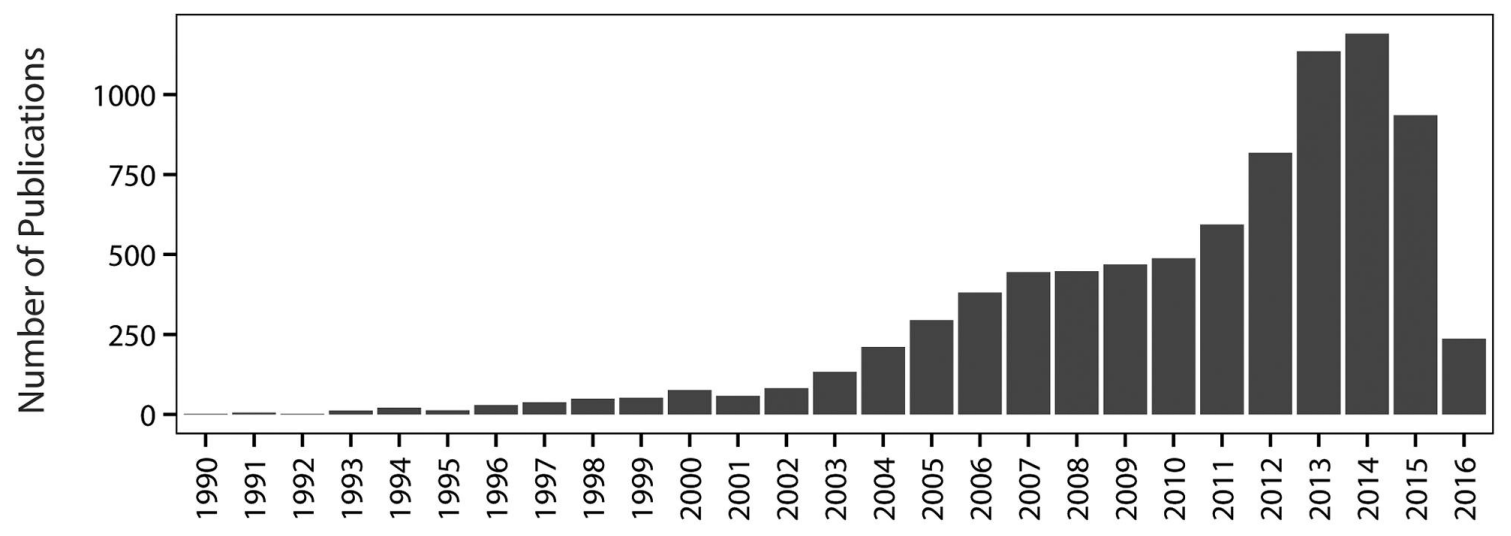

Year

Fig. 1. Number of publications annually in the ISI Web of Knowledge for a general search on ["UAV"] conducted in August 2016.

\section{UAS Review}

Primarily developed for military and espionage applications, UAS have become a popular multi-purpose tool for capturing high quality aerial data (Fig. 1; Pajares 2015). UAS can operate at much lower altitudes and achieve higher spatial resolutions than conventional aerial and satellite surveying techniques (Zhang et al. 2016). Research and development of UAS have focused on the ability to miniaturize, automate and enhance navigation, improve payload potential, and maximize flight times. The emergence of a booming commercial UAS sector, fueled by increasing price competition and simplified flight technologies, projects to more than a quadrupling of sales in the next five years (Peasgood and Valentin 2015). Although problems and limitations currently exist, technological innovations in GNSS and INS, digital camera and sensor technologies, geo-fencing and collision avoidance, and battery longevity, have allowed UAS to thrive in the commercial market, producing remote-sensing information close to, or better than, conventional aerial methods (Colomina and Molina 2014).

Previous reviews of UAS technology, such as Pajares (2015), outline the significant potential of these systems for improving agricultural and forestry efficiency, earthquake and oil spill disaster response, and soil and aquatic systems monitoring. Similarly, Blyenburgh and Co. (2014) provided a detailed review of optical remote sensing instrumentation, including active and passive visible, near infrared (NIR), thermal infrared (TIR), and microwave sensors mountable on commercially available UAS. In this paper we provide a condensed review about why UAS and DAP point clouds are increasingly being considered for the acquisition of high spatial resolution imagery.

\section{Airframes}

The current UAS market is diverse in terms of airframe type, size, and performance (Blyenburgh and Co. 2014). In general, the capacity of UAS for aerial surveying or geomatics pur- poses is determined by factors that are a function of size, including payload capacity, range, propulsion system, and cost (Stephens et al. 2000). Size classes, including micro, mini, standard, full size, and High Altitude Long Endurance (HALE), largely define the potential for the UAS to perform desired tasks. In general, the majority of UAS used for resource management and geomatics purposes are in the micro and mini classes, also known as tactical UAS (Nex and Remondino 2013). Two major airframe types (fixed-wing and rotary) are available in these size classes and costs generally range between CAD \$1000-\$150000, depending on the sophistication of onboard instruments, propulsion system, payload capacity, airframe type, and flight autonomy. Lower end options are generally unable to perform autonomous flights, almost always require user assistance for take-off and landing, and are limited to specific sensor models (Nex and Remondino 2013). As technology continues to develop, capabilities such as increased payload capacity to attach multiple sensors, improved range from battery or small engines, and completely autonomous pre-programmable flights are becoming more prevalent. Autonomous flight capabilities provide operators with a simple method of improving output data quality by maintaining flight elevation, speed, and trajectory (Siebert and Teizer 2014).

\section{Fixed-wing platforms}

Fixed-wing UAS consist of a single rigid wing with a predetermined aerofoil. Flight mechanics of fixed-wing UAS mimic conventional aeroplanes, where airspeed is generated by a propeller powered by an electric motor or combustion engine. Maneuverability during flights occurs through manipulation of ailerons, an elevator, and a rudder to control roll, pitch, and yaw. Advantages of these systems include simple maintenance, high flight speeds, and longer flight times, providing maximal area coverage at minimal costs. These characteristics make fixed-wing platforms ideal for larger scale mapping and surveying (Nex and Remondino 2013). 


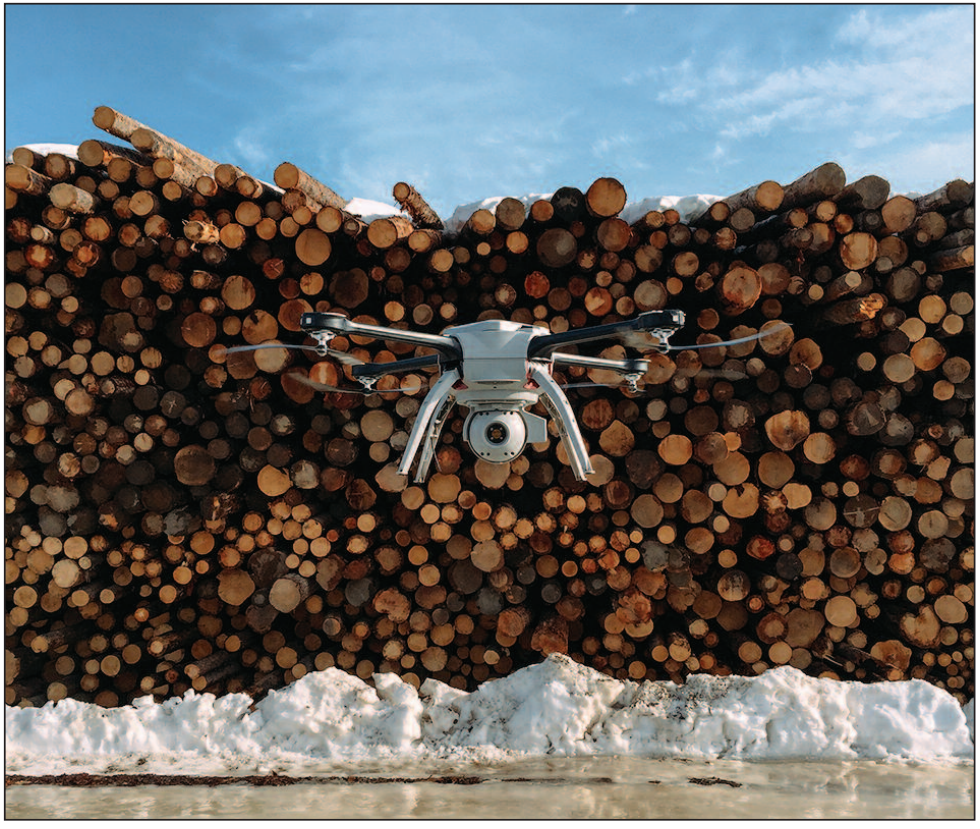

Fig. 2. Aeryon Skyranger quadcopter operated by Spire Aerobotics

Limitations to these systems are that they generally require a launcher or runway, although more expensive Vertical TakeOff and Landing (VTOL) and Short Take-Off and Landing (STOL) models can ameliorate these problems. Fixed-wing platforms are limited in that they must remain in a constant state of forward motion, nullifying their ability to collect imagery of objects that require stationary capture, such as hydro-electric or bridge inspection tasks (Montambault et al. 2010).

\section{Rotary platforms}

Rotary UAS have a high degree of mechanical complexity and customizability in terms of their hardware. Rotors attached to a fixed central mast allow the UAS to hover and fly in any direction. Rotor blades function in the same way as a fixedwing aerofoil; however, their ability to produce their own movement facilitates lift and flight (Fig. 2). Variation in thrust and torque of each rotor influences the overall movement of the UAS. The number of rotors on these platforms can range from one (helicopter), to three (tricopter), four (quadcopter), six (hexacopter), or even eight (octocopter) and above. Advantages of these systems are that they are capable of VTOL, allowing operators to launch in space-limited environments and have responsive movement and hover capabilities making them very well-suited to inspection-related tasks or where focus on specific objects is required (Montambault et al. 2010). The complexity and mechanically intricate designs of these systems can be disadvantageous as they require a higher degree of maintenance and larger draws on batteries or fuel to power. Comparatively high wind resistance, slower overall flight speeds, and increased power requirements mean these platforms have shorter ranges and consequently cover less area than fixed-wing platforms. These disadvantages generally mean that rotary UAS are more expensive and require more time to complete aerial surveying tasks.

Similarly to fixed-wing platforms, the price of rotary UAS is defined by software and hardware technologies. Higher complexity in flight maneuverability and control with rotary UAS increases the prices for models with fully autonomous flight capabilities. A large majority of rotary UAS are controlled using joystick controls, although fully autonomous models do exist.

\section{Sensor configurations}

Typical sensors and integrated instrumentation attached to conventional aircraft can weigh upwards of $50 \mathrm{~kg}$. Considering that UAS are highly limited in their payload capacity, drastic reductions in size and weight are needed for sensors to be compatible. An issue surrounding the attachment of sensors to UAS is that limitations to payload capacity and power draw requirements limit the compatibility of carrier and sensor. A discussion of sensors compatible with micro and mini UAS payload requirements can be found in Colomina and Molina (2014), who differentiated between visible-band, NIR, multispectral, hyperspectral, thermal, laser scanning, and synthetic aperture radar systems. Their review found that conventional high-resolution cameras were the dominant sensor being used, although multiple models of each sensor type exist with UAS compatibility.

Reductions in size and improvements in spatial resolution of visible-spectrum cameras have facilitated small, high-quality, low-cost sensor development such as those found on everyday smart-phone cameras (Fig. 3). The development of these sensors, along with 3D imaging software, has caused DAP usage to proliferate (Colomina and Molina 2014). The low cost of visible spectrum imagery collection and similarities of DAP point clouds to those produced from ALS sensors has prompted a dramatic increase in image-based point cloud research and commercial usage.

\section{UAS and forestry}

In order to improve the cost effectiveness and accuracy of operational forest inventories, forest managers require spatially and temporally accurate forest inventory data to make informed management decisions (Goodbody et al. 2016). Preliminary research has shown that images captured from UAS systems offer a definitive combination of very high resolution data capture at a consistently lower surveying cost (Wallace et al. 2012a). The capability for UAS to be deployed quickly and easily also facilitates updating inventories. Koh and Wich (2012) indicate that acquiring imagery and producing UAS-DAP point clouds could lead to significant reductions in capital and labour related costs, while also reducing the time needed for surveying.

The measurement of fundamental forest inventory parameters, such as tree height, has been a major focus for UAS research. Knowledge of the physical location and distribution of timber resources prior to field reconnaissance can improve productivity and eventual delineation of operational areas. Studies such as Wallace et al. (2014a), which used a UAS-ALS sensor, demonstrate the potential to measure tree heights at a similar precision to ground-based measurements. UAV-ALS have also indicated that measurements of tree height using these systems have the potential to be more accurate than those from conventional ALS data (Lin et al. 

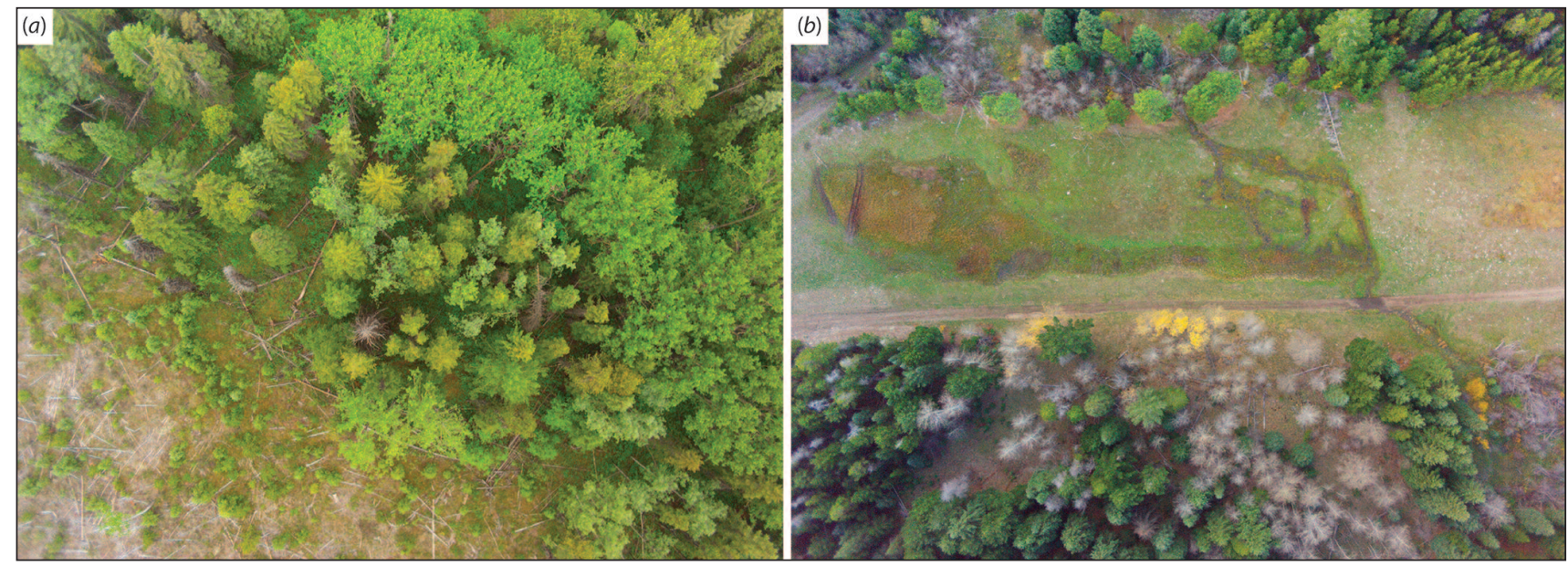

Fig. 3. UAS-acquired imagery using SUNEX MT9FOO2 RGB sensor at $100 \mathrm{~m}$ (a) and $200 \mathrm{~m}$ (b) above ground level

2011). Other research into UAS-ALS systems for forest inventory purposes, such as high resolution forest change detection (Wallace et al. 2012b), tree detection and crown segmentation (Wallace et al. 2014b), and fine scale forest mapping (Lin et al. 2011), indicate that UAS-ALS can extract information for forest inventory generation and monitoring at the stand and individual tree levels. The detailed and manipulatable nature of ALS point clouds shows strong potential to provide managers with information that increases the efficiency of forest reconnaissance at strategic and operational levels (Corona and Fattorini 2008).

While UAS-ALS combinations show promise for measuring forest inventory information, concerns about cost has been a limiting factor for their deployment. UAS-acquired imagery collected at an operational scale has been shown to be a relatively cheap and complimentary technology to conventional aerial photo surveying while providing point cloud outputs of similar quality and utility to ALS (White et al. 2015). Low cost, high spatial and temporal resolution data acquired using UAS-DAP point clouds have been shown to be accurate for observing phenological dynamics, spectral traits, monitoring changes, and measuring forested environments (Dandois and Ellis 2013). Tang et al. (2015) and Siebert and Teizer (2014) indicate that the collection of high resolution imagery using UAS-DAP should be encouraged for forestry purposes because it allows measurement of canopy and individual tree heights at lower costs than ALS systems. Depending on UAS flight parameters, ortho-mosaic imagery of forested areas can have spatial resolutions of $3-\mathrm{cm}$ or less, providing managers with ultra-high definition images of operational areas and a $3 \mathrm{D}$ point cloud in a single flight plan (Zhang et al. 2016). Apart from studies such as Zarco-Tejada et al. (2014), which demonstrated that optical imagery can be used to measure canopy heights at operational scales, UAS-DAP point clouds have been used for many other forestry purposes, including spatial quantification of riparian areas and determining vegetation composition (Dunford et al. 2009), mapping bark beetle damage at the individual tree level (Näsi et al. 2015), long-term forest monitoring (Zhang et al. 2016), and monitoring tropical forest recovery (Zahawi et al. 2015).

DAP is limited in that it cannot provide comprehensive structural information like ALS; however, the technique does produce a higher density surface model and includes spectral information (White et al. 2015). This balance between similarities in utility and differences in output products promotes their tandem utilization as a spatially and temporally accurate forest monitoring framework without burdening the manager with redundant information (Wallace et al. 2012a). Studies into the synthesis of ALS and UAS-DAP point clouds, such as Goodbody et al. (2016), have shown that it is possible to use UAS-DAP point clouds to outline the location and estimate residual timber volume following selection harvesting operations.

A combination of hardware limitations, such as the longevity of propulsion systems, and current federal transport regulations, such as the requirement to always have line-of-sight with the UAS being flown, restrict the applicability of UAS for the mapping and/or imaging of large areas (Transport Canada 2014). However, UAS-DAP has potential to improve managerial knowledge of the land base at the local operational scale by updating areas where imagery was previously collected or establishing new baseline inventory information. As technology, federal regulations, and knowledge of UAS mapping and inventory capabilities evolve, their use in large-scale mapping procedures should become more prevalent.

\section{Case Study \\ Methods}

Given the growing body of research incorporating UAS, we sought to examine their effectiveness from a precision forest inventory context. To do so, we present a case study where UAS-DAP point clouds were used to update a previously established ALS EFI to demonstrate the potential use of this technology in a more operational context. Point cloud outputs from ALS in 2013 and DAP in 2015 were used to determine UAS-DAP point clouds legitimacy as a forest inventory updating tool. To identify the validity of using multiple point cloud metrics for measuring height growth, both the CHM and $95^{\text {th }}$ percentile of height (P95) were analyzed. The ALS and DAP point cloud data were collected from the same 31.6 ha compartment within the Knife Creek block of the University of British Columbia's Alex Fraser Research Forest (AFRF), located south of 150 Mile House, British Columbia (Longitude $121^{\circ} 48^{\prime} \mathrm{W}$, Latitude $52^{\circ} 03^{\prime} \mathrm{N}$ ). 
The Knife Creek block is situated in the Interior Douglasfir biogeoclimatic ecosystem classification zone with gently sloping terrain and dry to very dry climate (Hope et al. 1991). The forest is largely dominated by uneven-aged Douglas-fir (Pseudostuga menzieszii var. glauca (Beissn.) Franco) with intermittent lodgepole pine (Pinus contorta Dougl. ex Loud. var. latifolia Engelm.). This study is among the first to evaluate UAS technology as a tool to update sampling for existing ALS-generated EFIs. Motivations for this analysis included maximizing the temporal accuracy and cost effectiveness of the EFI, as well as monitoring tree height and volume growth over the inter-inventory period.

\section{ALS collection}

The acquisition of ALS data in August 2013 was a large-scale operation to fully map the 3484 ha Knife Creek block of AFRF. A Cessna was flown approximately $600 \mathrm{~m}$ above ground level with a Riegl VQ-580 laser scanner operating at $200 \mathrm{kHz}$. The scanner collected data $\pm 30^{\circ}$ from nadir, with a density averaging between 7-9 points $\mathrm{m}^{-2}$ for all returns, with an estimated vertical root mean squared error (RMSE) of $0.048 \mathrm{~m}$.

\section{DAP collection}

A VTOL quadcopter was used in March 2015 to acquire over 2300 red-green-blue (RGB) images. A 16-megapixel camera was attached at nadir and flown at a consistent altitude of 100 $\mathrm{m}$. The flight plan was designed to ensure a high percentage of along $(\sim 85 \%)$ and across track $(\sim 65 \%)$ overlap between collected images. Image acquisition took place over several hours in benign sun and wind conditions. Upon completion, Pix4D SGM software was used to produce both a high resolution DAP point cloud and an ortho-mosaic image of the site area. Horizontal and vertical accuracies of the DAP point clouds were $\pm 6 \mathrm{~cm}$ and $9 \mathrm{~cm}$ respectively.

\section{Point cloud processing}

Ground returns from the ALS point cloud were isolated to produce a DEM and to normalize the point cloud. Maximum point heights were used to create a Digital Surface Model (DSM). The difference between the DSM and DEM produced a $0.5 \mathrm{~m}$ Canopy Height Model (CHM). DAP processing followed the same procedure described above, except the DAP point cloud was first co-registered using the ALS point cloud as reference, then normalized using the ALS-derived DEM. The ALS-derived DEM was used, as it has been shown to be superior to aerial imaging techniques for mapping terrain (Holopainen et al. 2015).

Co-registration between the two datasets was performed by using prominent and permanent landmarks such as operational landings, road intersections, and adjacent pipeline features in the ALS point cloud as ground control points. Features were then matched in the DAP dataset to allow the ALS DEM to be used for accurate point cloud normalization. The small size of the study area and the relatively low terrain variation across the site facilitated this co-registration of the two point clouds. In more complex terrain or over large areas coregistration can be more challenging.

\section{Tree identification and delineation}

To compare the maximum tree heights from the two CHMs, 20 image plots, each $20 \times 20 \mathrm{~m}$, were established within the study area in parts of the stand that were undisturbed between 2013 and 2015. The CHM of each image plot with a $10 \mathrm{~m}$ buffer was extracted and individual trees were identified using a local maxima search followed by crown delineation routines (Tompalski et al. 2014). Image plot extents were overlaid on the CHM and all detected treetops within the bounds were included. Individual trees were assigned CHMderived heights. Treetop locations and crown extents for both ALS and DAP datasets were processed to ensure the same trees were identified across both datasets. Identified trees were classified as being detected in both datasets or in one dataset only. Trees matched in both datasets were principally dominant individuals in the canopy with the most prominent crowns. For the purposes of this analysis, it was assumed that all matched trees were Douglas-fir.

\section{Height and volume comparison}

Individual matched tree height metrics, produced from both the CHM and P95 in both the ALS and DAP datasets for all image plot locations, were compared (White et al. 2015). CHM heights were validated using independent field-measured sample plots in the same study area at the time of ALS and imagery collection. The ALS CHM was shown to under predict tree height by $4 \%$. This was likely due to laser pulses not intersecting tree apexes. As a result, a correction factor was applied (Yu et al. 2004). Validation indicated that the DAP CHM did not experience the same problem due to the much denser point cloud.

In order to generate gross volume estimates for all matched trees, diameter at breast height $(\mathrm{DBH})$ for all subject trees was required. To estimate these values, tree crown areas and their corresponding CHM and P95 heights from locally validated samples were fit using local data in the following equation (Hall et al. 1989):

[1] $D B H=e^{2.590283+0.043808 \times H-0.001381 \times C A}$

Where $\mathrm{DBH}$ is diameter at breast height in $\mathrm{cm}, \mathrm{H}$ is tree height in $\mathrm{m}$, and CA is crown area in $\mathrm{m}^{2}$.

After DBH was estimated for each tree, DBH as well as $\mathrm{CHM}$ and $\mathrm{P} 95$ heights were used as inputs for a Douglas-fir gross volume equation (BC Forest Service 1976):

[2] $\mathrm{V}=10^{-4.383102+1.749240 \times \log _{10}(D B H)+1.156410 \times \log _{10}(H)}$

Where $\mathrm{V}$ is tree volume in $\mathrm{m}^{3}$ and $\mathrm{DBH}$ and $\mathrm{H}$ are as defined previously.

Height and volume estimates for matched trees were compared with local independent field-measured plots averaged over 21 years of measurements. Sampling methodologies for these plots can be found in Marshall (1996). The most recent re-measurement period for these plots was completed at the end of the 2013 growing season.

\section{Results}

A total of 246 trees were detected across all image plots with $171(70 \%)$ being detected in both data sets. The remaining trees were detected in only one of the data sets (30 in the ALS and 45 in the DAP). Both the CHM and P95 heights of matched trees from all image plots were compared (Fig. 4; Fig. 5). Mean height growth for all trees over the inter-inventory period was $0.68 \mathrm{~m}$, with a standard error of $0.05 \mathrm{~m}$ for the CHM, while P95 height increased by $0.50 \mathrm{~m} \pm 0.05 \mathrm{~m}$. 


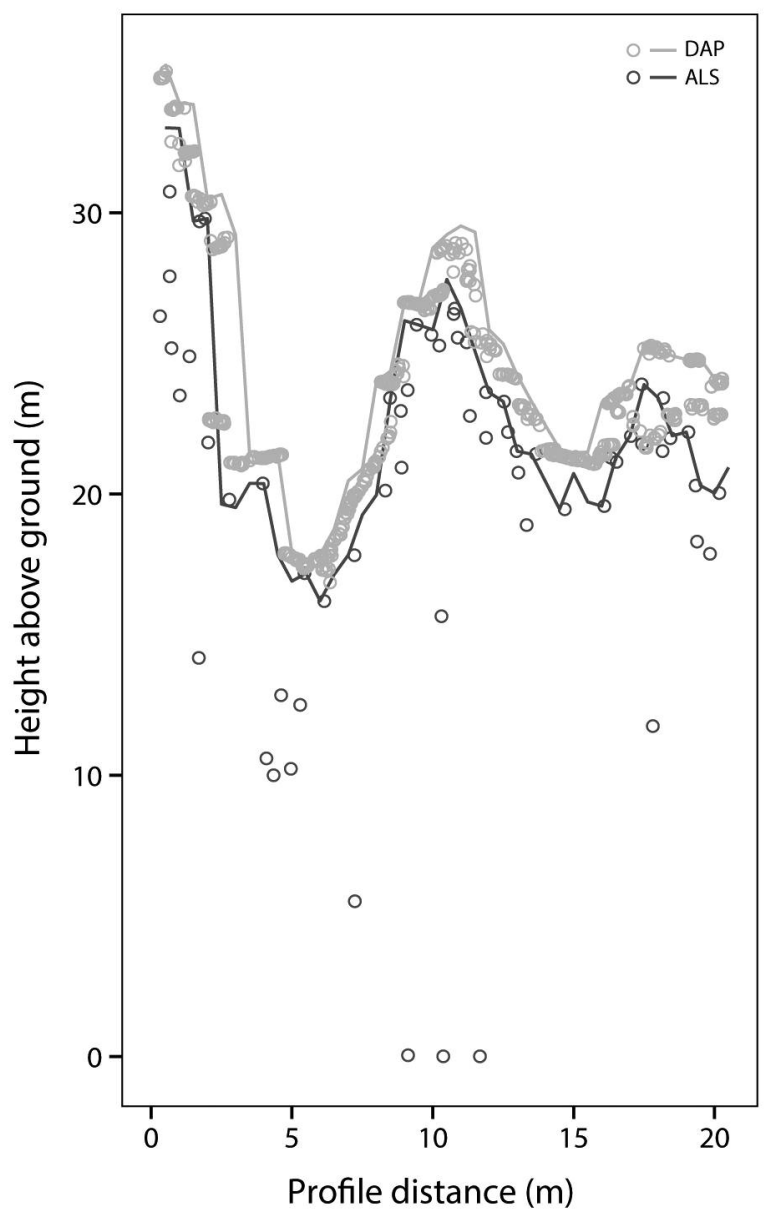

Fig. 4. Canopy height model (CHM) height profile (m) of 2013 ALS (dark grey) and 2015 DAP (light grey) and associated point clouds denoted by circles. Tree tops can clearly be identified in both data sets, outlining how the CHM local maxima were used to delineate crown extents and estimate heights.

Height growth was detected for 152 trees while 19 trees showed a reduction in height. Measured growth of well-growing trees on independent field-measured sample plots indicated average annual growth rates of $0.25 \mathrm{~m}$ to $0.30 \mathrm{~m}$ over 21 years of measurements. Gross volume estimates for each matched tree were produced using CHM and P95 derived heights and modelled $\mathrm{DBH}$ values. $\mathrm{CHM}$ gross volume increased by an average of $0.05 \mathrm{~m}^{3} \pm 0.005 \mathrm{~m}^{3}$ (Fig. 6), while P95 gross volumes indicated slightly less growth of $0.03 \mathrm{~m}^{3} \pm$ $0.005 \mathrm{~m}^{3}$ over the inter-inventory period (Fig. 7).These levels of tree volume growth slightly exceeded the growth found on the independent sample in area (average $\sim 0.01 \mathrm{~m}^{3}$ per year over the last 21 years).

\section{Discussion}

The 2013 ALS data generated a baseline individual tree level inventory, providing height, structure, and location information for each detected tree. The comparison of ALS- and UAS-acquired DAP point cloud height data from both the
CHM and P95 height in our analysis indicated that individual trees can be matched across data types to update height and volume for individual tree level inventories. Height and volume results indicate that UAS acquired DAP CHM and P95 can be used for measuring growth. The technique developed in the paper facilitated synthesis between the ALS- and UASDAP point clouds in our study area to produce individual tree inventory data, following the movement towards precision forestry at local and regional scales (Holopainen et al. 2014).

UAS-DAP point clouds were effective in updating individual tree growth and volume between 2013 and 2015. Estimates were within the limits of regional growth models (Thrower and Goudie 1992) and local independent fieldmeasured sample plot data. CHM and P95 data both indicated that height growth decreased as total tree height increased, potentially due to slowing of productivity associated with mature individuals. Individual tree volume showed the opposite trend, where the volume increment increased with larger trees. This finding agrees with assumptions that larger, taller trees may be exhibiting slower primary growth, but that increased basal areas result in larger annual volume increments. Past research into the relationship between ALS and DAP point cloud metrics has shown that correlations between the two data types increase as height percentiles increase (Goodbody et al. 2016). Both the CHM and P95 heights were analysed in our study to outline the consistency in growth and volume estimations between the two metrics, but also to indicate that both are highly correlated and reliable for measuring forest inventory metrics (White et al. 2013a).

Both point clouds are not error free. Due to the relatively lower point density of ALS compared to the DAP point cloud, it is unlikely that the absolute apex of each crown was detected (Ontiveros et al. 2005). It was for this reason that a height correction factor produced from independently fieldmeasured sample plots from the same ALS dataset was applied to all ALS trees. Other issues that should be noted are the potential for artifacts within individual tree crowns. The cumulative error of the ALS and DAP point cloud data must be considered when utilizing the data being presented. Although a predominant portion of the matched trees showed height growth and volume increases, some trees were slightly shorter and indicated less volume in 2015 than in 2013, which could be artifacts from the CHM and P95 heights as well as DBH modelling. To more precisely quantify the decreases in height associated with natural occurrences such as leader breakage, manual field measurements would be needed.

The relatively short period from 2013 to 2015 between data set collections could also have introduced inaccuracy due to measurement and precision errors potentially being within the physical limits of tree growth. In order to ameliorate the potential for these errors in future studies, a framework to consider could involve broad scale ALS acquisition at 10-15 year intervals with regular 4-6 year UAS-DAP point cloud updates for mature stands (White et al. 2013a). Although much more frequent than current forest management standards, higher periodicity of inventory updates could help to improve growth and yield estimates, while also providing spatial and structural information related to areas of potential growth deficiency, competition concern, or treatment successes and failures. 


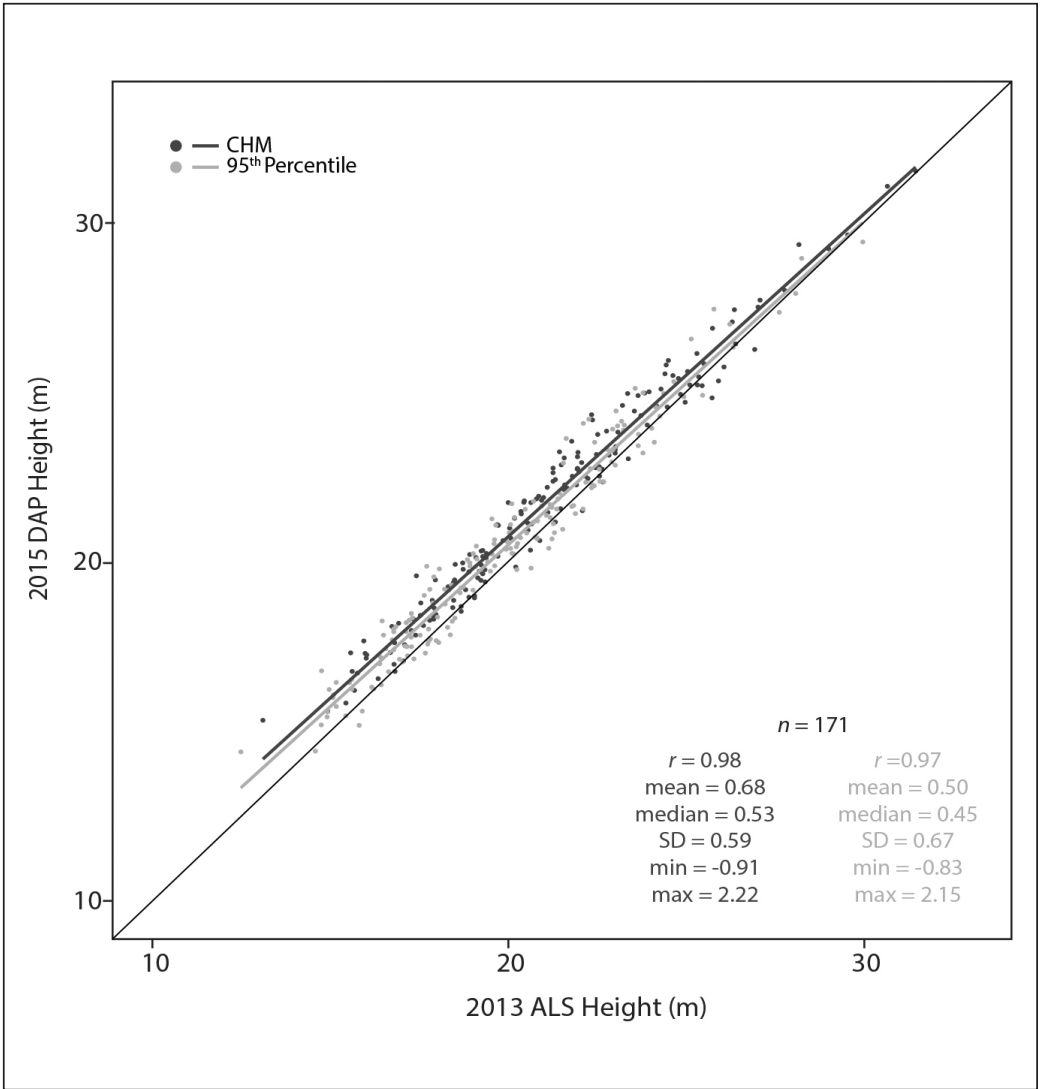

Fig. 5. Comparison of tree heights $(\mathrm{m})$ for all ALS and DAP trees from the CHM (dark grey) and 95th percentile of height (light grey) along with tree growth statistics. 1:1 line shown.
Descriptive statistics for individual trees provide managers with data that allow for resource monitoring and guiding future harvest planning. Creation of conventional tabular information paired with the $3 \mathrm{D}$ point cloud in the form of an EFI can allow managers to better understand the development of composition, structure, and depending on sensors, potentially the health of the trees on their land base (Näsi et al. 2015). The ability to quickly operationalize UAS for DAP point cloud acquisition also facilitates inventory updates in the event of an unforeseen disturbance or scheduled harvesting. The proposed inventory updating framework has the potential to maintain temporal and spatial accuracy of operational areas, allowing managers to have consistently reliable forest resource information (Lisein et al. 2013).

Estimating gross volume for individual trees increases the precision of forestry practices and provides a basis for estimating the economic value of timber that metrics such as tree height alone cannot. Managerial knowledge of how tree volume is changing from year to year across their land base not only facilitates an informed long-term planning process to maximize revenue from harvesting operations, but also allows the prioritization of where and when operations are conducted. Having multiple long-term plans for operations can reduce future economic

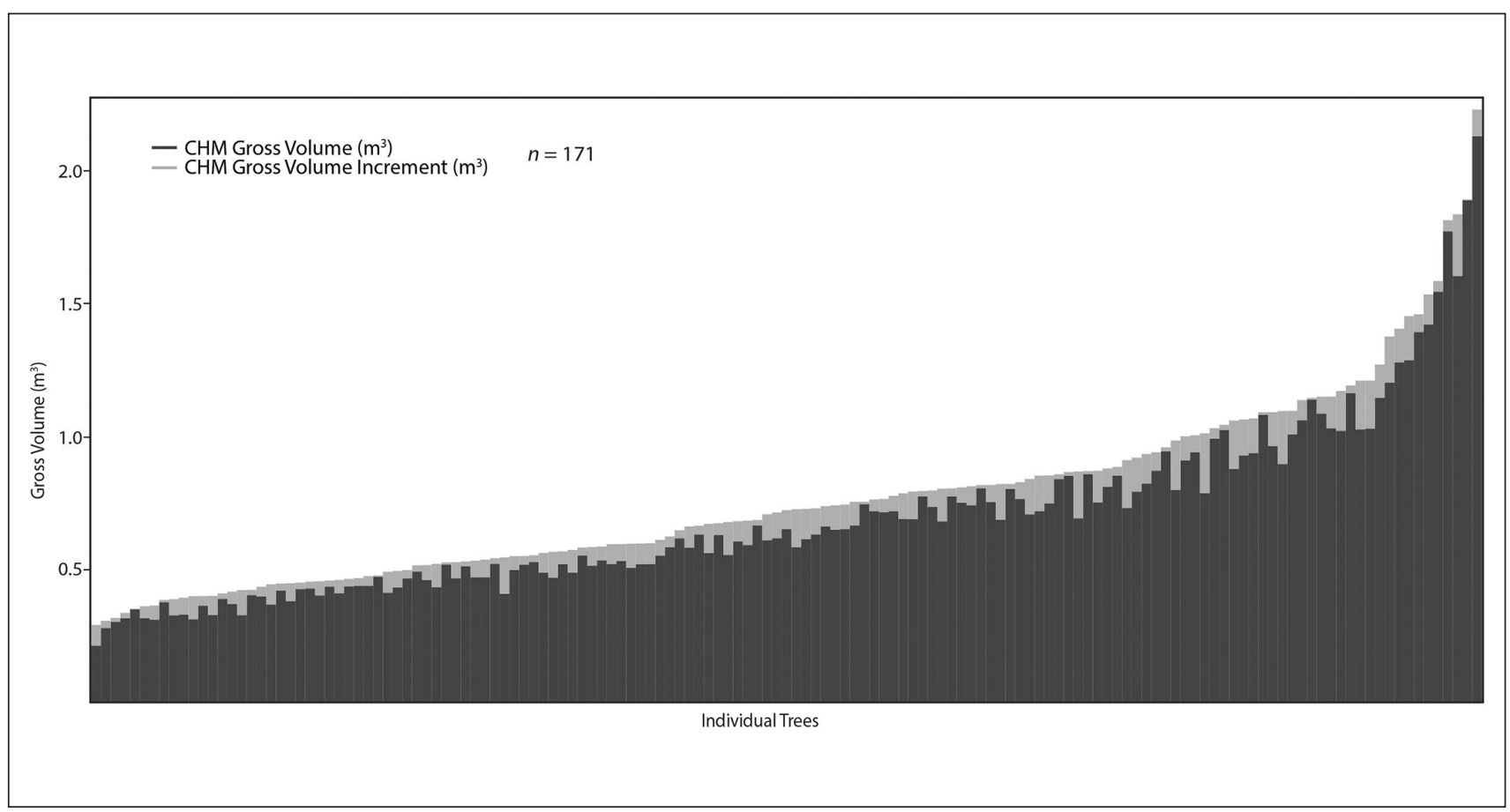

Fig. 6. Histogram of all 171 individually matched trees with their $2013 \mathrm{CHM}$ gross volume $\left(\mathrm{m}^{3}\right.$ ) estimates (dark grey) and corresponding gross volume $\left(\mathrm{m}^{3}\right)$ increment estimates (light grey). The sum of the gross volume and increment equates to the CHM gross volume estimate for 2015. 


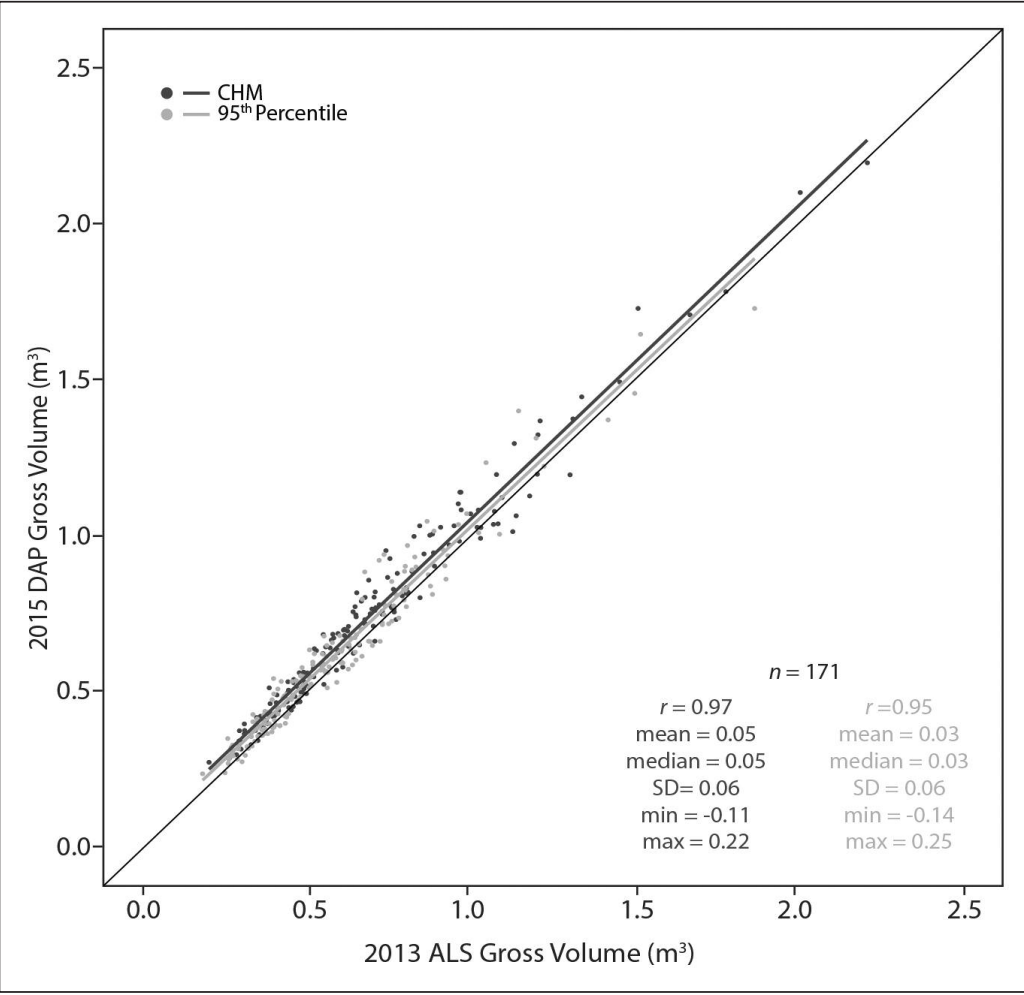

Fig. 7. Comparison of gross volumes $\left(\mathrm{m}^{3}\right)$ for all ALS and DAP trees from the CHM (dark grey) and 95th percentile of height (light grey) along with volume increase statistics. 1:1 line shown

uncertainty and help guide corporate development. The combination of individual tree volumes, heights, and locations could be used to guide operational planning. Determining individual trees and areas that are suitable for harvesting now or in the near future increases economic and environmental sustainability while promoting progressive and precise forest stewardship and planning.

An inventory framework such as the one presented here has the potential to be used as an ecosystem-based management and monitoring tool (Zhang et al. 2016). Having a baseline and routinely updated EFI for a forest stand or harvested area may identify areas that are in need of treatments such as thinning or application of herbicide or fertilizer, and how they could respond post-treatment. Having accurate spatial knowledge of specific locations requiring treatments rather than a large-scale application of treatments will reduce application time and costs. By using UAS to collect DAP point clouds prior to, and after applications, managers can gauge successes and failures, and modify future actions based on their findings.

Similarly, a multi-temporal EFI framework could help guide decision-making about the location and characteristics of desirable timber. Such data can reduce the labour and time intensity of field reconnaissance so resources can be allocated more effectively. As technological advancements and reductions in cost for UAS-compatible ALS sensors become more prevalent, the widespread collection of these data will become more prominent (Zhang et al. 2016). The landscape level coverage of ALS data provides managers with spatially and temporally accurate models of operational areas. Block develop- ment and site plan information related to road and skid trail planning, presence and locations of streams and archaeological sites, stratification of stand types, and accurate estimates of fundamental tree parameters such as height and volume, provide planning and operational information from which managers can make informed decisions on harvest methodologies and timing. Information on terrain and stand characteristics can help guide managers in optimizing harvest equipment being deployed to harvesting sites, thus reducing logging costs and improving the efficiency of operations. EFI information about log volumes prior to harvest can be used in conjunction with current market climates to allow for better planning in the appropriate allocation of timber to specialist mills for higher value end-product generation. All of these operational decisions have significant effects on the overall cost, efficiency, and sustainability of operations.

Given that $70 \%$ of trees were matched across datasets, further research into the improvement of tree detection and crowngrowing algorithms is needed to improve the accuracy and reliability of individual tree inventories. Of the individual trees that were matched, a majority were dominant in the canopy. For this reason, research into refining the detection and matching of non-dominant stems within stands would help to improve overall detection and matching accuracies. The incorporation of spectral data from UAS ortho-imagery, which is already used in the DAP process along with CHMs, could help to refine tree detection and matching methodologies. Furthermore, acquiring high resolution visible as well as NIR imagery could help to improve accurate identification of individual tree species, health, and outline potential areas of management concern (Näsi et al. 2015). Accurate species identification will reduce uncertainty in applying species-specific DBH and volume models in mixed stands, increasing the scope of our case study methodology. To improve the spatial accuracy of future DAP point clouds, we recommend the incorporation of ground control points during the data collection phase as in Dandois and Ellis (2010).

\section{Conclusion}

Our review into current commercial UAS and sensor technologies has outlined their potential to improve the costeffectiveness and quality of aerial imaging for forestry applications. Our case study confirmed these benefits and illustrates an effective method to update pre-existing ALS EFIs. The ability to produce tree height and volume growth estimates using both ALS and DAP point clouds over time provides spatial and quantitative data that can guide future operational decisions. With ongoing research and development, generating and updating EFIs using ALS- and UASDAP point clouds will likely become the standard for providing informative, cost-effective, and spatially accurate information in support of precision forest management. 


\section{Acknowledgements}

We thank an anonymous foundation for providing the funding that made this research possible. We also thank AFRF staff Ken Day and Cathy Koot for providing the ALS data for this study, and Spire Aerobotics for acquiring and pre-processing the DAP data. We are also very appreciative to the reviewers for their significant effort and dedication to this study.

\section{References}

BC Forest Service. (1976). Whole Stem Cubic Metre Volume Equations and Tables: Centimetre Diameter Class Merchantable Volume Factors. Victoria, BC: Forest Inventory Division, British Columbia Forest Service. 206 p.

Bechtold, W.A., and P.L. Patterson. (2005). The enhanced forest inventory and analysis program: National sampling design and estimation procedures. Available from Available from http://www.srs.fs. usda.gov/pubs/gtr/gtr_rs080/gtr_srs080.pdf

Blyenburgh and Co. (2014). R2014 RPAS Yearbook - RPAS: The Global Perspective. (P. van Blyenburgh, ed.) (12 ${ }^{\text {th }}$ ed.). 240 p. Paris: Blyenburgh and Co. Available from http://uvs-info.com/index.php/ yearbooks/yearbook-2014-v2

Colomina, I., and P. Molina. (2014). Unmanned aerial systems for photogrammetry and remote sensing : A review. ISPRS J. Photogram. 92: 79-97. https://doi.org/10.1016/j.isprsjprs.2014.02.013

Corona, P. and L. Fattorini. (2008). Area-based LiDAR-assisted estimation of forest standing volume. Can. J. Forest Res. 38(11): 2911-2916. https://doi.org/10.1139/X08-122

Dandois, J.P. and E. Ellis. (2010). Remote sensing of vegetation structure using computer vision. Remote Sens. 2(4): 1157-1176. https://doi.org/10.3390/rs2041157

Dandois, J.P. and E.C. Ellis. (2013). High spatial resolution threedimensional mapping of vegetation spectral dynamics using computer vision. Remote Sens. Environ. 136: 259-276. https://doi.org/ 10.1016/j.rse.2013.04.005

Dunford, R., K. Michel, M. Gagnage, H. Piégay and M.L. Trémelo. (2009). Potential and constraints of Unmanned Aerial Vehicle technology for the characterization of Mediterranean riparian forest. Intern. J. Remote Sens. 30(19): 4915-4935. https://doi.org/10.1080/ 01431160903023025

Goodbody, T.R.H., N.C. Coops, P. Tompalski, P. Crawford and K.J.K. Day. (2016). Updating residual stem volume estimates using point clouds. Intern. J. Remote Sens. 1161(August). https://doi.org/ 10.1080/01431161.2016.1219425

Hall, R.J., R.T. Morton and R.N. Nesby. (1989). A comparison of existing models for DBH estimation from large-scale photos. Forest. Chron. 65(2): 114-120.

Hilker, T., M.A. Wulder and N.C. Coops. (2008). Update of forest inventory data with LiDAR and high spatial resolution satellite imagery. Can. J. Remote Sens. 34(1): 5-12. https://doi.org/10.5589/ m08-004

Hirschmüller, H. (2005). Accurate and efficient stereo processing by semi-global matching and mutual information. IEEE Computer Society Conference on Computer Vision and Pattern Recognition 2: 807-814. https://doi.org/10.1109/CVPR.2005.56

Holopainen, M., M. Vastaranta and J. Hyyppä. (2014). Outlook for the next generation's precision forestry in Finland. Forests 5 : 1682-1694. https://doi.org/10.3390/f5071682

Holopainen, M., M. Vastaranta, M. Karjalainen, K. Karila, S. Kaasalainen and E. Honkavaara. (2015). Forest inventory attribute estimation using airborne laser scanning, aerial stereo imagery, radargrammetry and interferometry - Finnish experiences of the 3D techniques. ISPRS Ann. Photogram. Remote Sens. Spatial Inform. Sci. 2: 25-27. https://doi.org/10.5194/isprsannals-II-3-W4-63-2015
Hope, G.D., W.R. Mitchell, D.A. Lloyd, W.R. Erickson, W.L. Harper and B.M. Wikeem. (1991). Interior Douglas-fir zone. In: Meidinger, D. and J. Pojar (eds.). Ecosystems of British Columbia (pp. 153-166). B.C. Ministry of Forests, Victoria.

Koh, L.P., and S.A. Wich. (2012). Dawn of drone ecology: Low-cost autonomous aerial vehicles for conservation. Trop. Conserv. Sci. 5(2): 121-132

Lin, Y., J. Hyyppä and A. Jaakkola, A. (2011). Mini-UAV-borne LiDAR for fine-scale mapping. IEEE Geoscience and Remote Sensing Letters 8(3): 426-430. https://doi.org/10.1109/LGRS.2010.2079913 Lindquist, E. et al. (2012). Global forest land-use change 1990-2005. FAO Forestry Paper No. 169. Food and Agriculture Organization and European Commission Joint Research Centre. Rome: FAO.

Lisein, J., M. Pierrot-Deseilligny, S. Bonnet and P. Lejeune. (2013). A photogrammetric workflow for the creation of a forest canopy height model from small Unmanned Aerial System Imagery. Forests 4(4): 922-944. https://doi.org/10.3390/f4040922

Marshall, P. (1996). FRDA 242 - Response of uneven-aged Douglasfir to alternative spacing regimes: Analysis of the initial impact of the spacing regimes. NRCanada and B.C. Ministry of Forests, Victoria. FRDA Report \# 242.

McGlone, J., E. Mikhail, J. Bethel and R. Mullen. (2004). Manual of Photogrammetry. American Society of Photogrammetry and Remote Sensing ( $5^{\text {th }}$ ed.). 1151 p. Am Soc. Photogram. Remote Sens. Bethesda, Maryland.

Montambault, S., J. Beaudry,K, Toussaint N. and Pouliot. (2010). On the application of VTOL UAVs to the inspection of power utility assets. $1^{\text {st }}$ International Conference on Applied Robotics for the Power Industry 1-7. Available from http://ieeexplore.ieee.org/xpls/ abs_all.jsp?arnumber $=5624443$ andtag $=1$

Näsi, R. et al. (2015). Using UAV-based photogrammetry and hyperspectral imaging for mapping bark beetle damage at tree level. Remote Sens. 7(11): 15467-15493. https://doi.org/10.3390/ rs71115467

Nex, F. and F. Remondino. (2013). UAV for 3D mapping applications: A review. Appl. Geomat. 6(1): 1-15. https://doi.org/10.1007/ s12518-013-0120-x

Ontiveros, C., S. Smith, S. Snape and J.C. Sua. (2005). Use of airborne LiDAR and aerial photography in the estimation of individual tree heights in forestry. Comput. Geosci. 31(2): 253-262. https:// doi.org/ 10.1016/j.cageo.2004.09.015

Pajares, G. (2015). Overview and current status of remote sensing applications based on Unmanned Aerial Vehicles (UAVs ). Photogramm. Eng. Rem. S. 81(4): 281-329. https://doi.org/10.14358/ PERS.81.4.281

Peasgood, S. and M. Valentin. (2015). Report - Drones: A Rising Market. 11 p. Available from http://sophiccapital.com/wp-content/ uploads/2015/09/Download-Sophic-Capitals-Aerial-DroneReport-Here.pdf

Siebert, S. and J. Teizer. (2014). Automation in Construction Mobile 3D mapping for surveying earthwork projects using an Unmanned Aerial Vehicle (UAV) system. Automat. Constr. 41: 1-14. https://doi.org/10.1016/j.autcon.2014.01.004

Silva, C., A. Hudak, N. Crookston, C. Silva and V. Liesenberg. (2014). Extracting individual trees and LiDAR metrics using a webLiDAR forest inventory application. Part 3: The 3D ClusterTree tool. 11th Seminar on Remote Sensing and GIS Applications in Forest Enginnering (July 2015), Curitiba, Brazil. https://doi.org/10.13140/ 2.1.2729.5688

Stephens, G.L., R.G. Ellingson, W. Bolton, T.P. Tooman and F.P.J. Valero. (2000). The Department of Energy's Atmospheric Radiation Measurement (ARM) Unmanned Aerospace Vehicle (UAV) program. B. Am. Meteorol. Soc. 81(12): 2915-2937. https://doi.org/ 10.1175/1520-0477(2000)081<2915:TDOESA >2.3.CO;2 
Tang, L. and G. Shao. (2015). Drone remote sensing for forestry research and practices. J. Forest. Res. 26(4): 791-797. https://doi.org/ 10.1007/s11676-015-0088-y

Tao, W., Y. Lei and P. Mooney. (2011). Dense point cloud extraction from UAV-captured images in forest area. ICSDM 2011 - Proceedings 2011 IEEE International Conference on Spatial Data Mining and Geographical Knowledge Services: pp. 389-392. https://doi.org/ 10.1109/ICSDM.2011.5969071

Thrower, J.S. and J.W. Goudie. (1992). Development of height-age and site-index functions for even-aged interior Douglas-fir in British Columbia. BC Ministry of Forests. Res. Note \# 109, 22 p. Victoria.

Tompalski, P., P. Wężyk, M. Weidenbach, R. de Kok and P. Hawryło. (2014). A comparison of LiDAR and Image-Derived Canopy Height models for individual tree crown segmentation with object-based image analysis. SE. Eur. J. Earth Observ. Geomat. 3(2S): 1-4. Tomppo, E., T. Gschwantner, M. Lawrence and R.E. McRoberts. (2010). National Forest Inventories Pathways for Common Reporting. Springer Netherlands. https://doi.org/10.1007/978-90-481-3233-1

Transport Canada. (2014). Guidance Material for Operating Unmanned Air Vehicle Systems under an Exemption. Advisory Circular \# 600-004 (2). 31 p.

Wallace, L., A. Lucieer, C. Watson and D. Turner. (2012a). Development of a UAV-LiDAR system with application to forest inventory. Remote Sens. 4(6): 1519-1543. https://doi.org/10.3390/rs4061519

Wallace, L., A. Lucieer and C.S. Watson. (2012b). Assessing the Feasibility of UAV-based LiDAR for High Resolution Forest Change Detection. ISPRS - Intern. Arch. Photogram. Remote Sens. Spatial Inform. Sci. 38 (August): 499-504. https://doi.org/10.5194/ isprsarchives-XXXIX-B7-499-2012

Wallace, L., R. Musk and A. Lucieer. (2014a). An assessment of the repeatability of automatic forest inventory metrics derived from UAV-borne laser scanning data. IEEE T. Geosci. Remote 52(11): 7160-7169. https://doi.org/10.1109/TGRS.2014.2308208

Wallace, L., A. Lucieer and C.S. Watson. (2014b). Evaluating tree detection and segmentation routines on very high resolution UAVLiDAR ata. IEEE T. Geosci. Remote 52(12): 7619-7628. https:// doi.org/10.1109/TGRS.2014.2315649
Wehr, A. and U. Lohr. (1999). Airborne laser scanning-an introduction and overview. ISPRS J. Photogram. Remote Sens. 54 (2-3): 68-82. https://doi.org/10.1016/S0924-2716(99)00011-8

White, J., C. Stepper, P. Tompalski, N. Coops and M. Wulder. (2015). Comparing ALS and image-based point cloud metrics and modelled forest inventory attributes in a complex coastal forest environment. Forests 6(10): 3704-3732. https://doi.org/10.3390/f6103704 White, J., M.A. Wulder, M. Vastaranta, N.C. Coops, D. Pitt and M. Woods. (2013a). The utility of image-based point clouds for forest inventory: A comparison with airborne laser scanning. Forests 4(3): 518-536. https://doi.org/10.3390/f4030518

White, J., M.A. Wulder, M. Varhola, M.Vastaranta, N.C. Coops, B. Cook, D. Pitt and M. Woods. (2013b). A best practices guide for generating forest inventory attributes from airborne laser scanning data using an area-based approach. Forest. Chron. 89(6): 722-723. https://doi.org/10.5558/tfc2013-132

Wulder, M.A., C. Bater, N.C. Coops, T. Hilker and J. White. (2008). The role of LiDAR in sustainable forest management. Forest. Chron. 84(6): 807-826. https://doi.org/10.5558/tfc84807-6

Yu, X., J. Hyyppa, H. Kaartinen and M. Maltamo. (2004). Automatic detection of harvested trees and determination of forest growth using airborne laser scanning. Remote Sens. Environ. 90: 451-462. https://doi.org/10.1016/j.rse.2004.02.001

Zahawi, R.A., J.P. Dandois, K.D. Holl, D. Nadwodny, J.L. Reid and E.C. Ellis. (2015). Using lightweight unmanned aerial vehicles to monitor tropical forest recovery. Biol. Conserv. 186: 287-295. https://doi.org/10.1016/j.biocon.2015.03.031

Zarco-Tejada, P.J., R. Diaz-Varela, V. Angileri and P. Loudjani. (2014). Tree height quantification using very high resolution imagery acquired from an unmanned aerial vehicle (UAV) and automatic 3D photo-reconstruction methods. Eur. J. Agron. 55: 89-99. https://doi.org/10.1016/j.eja.2014.01.004

Zhang, J., J. Hu, J. Lian, Z. Fan, X. Ouyang and W. Ye. (2016). Seeing the forest from drones: Testing the potential of lightweight drones as a tool for long-term forest monitoring. Biol. Conserv. 198: 60-69. https://doi.org/10.1016/j.biocon.2016.03.027 